Disclosure of Interest: None declared

DOI: 10.1136/annrheumdis-2018-eular.5340

\section{FRI0563 MUSCULOSKELETAL ULTRASOUND (MSUS) IS SUPERIOR TO CLINICAL EXAMINATION REGARDING DETECTION OF ARTHRITIS IN PATIENTS WITH SYSTEMIC SCLEROSIS}

D. Feldmann ${ }^{1}$, R.E. Voll ${ }^{1}$, F. Kollert ${ }^{2}$, S. Finzel ${ }^{1} .{ }^{1}$ Department of Rheumatology and Clinical Immunology, University Medical Center Freiburg, Freiburg, Germany;

${ }^{2}$ Department of Rheumatology, Immunology, and Allergology, Inselspital, University Hospital Bern, Bern, Switzerland

Background: Arthralgia is a frequent complaint in patients with systemic sclerosis (SSc). However, correct assessment of arthritis remains challenging especially in patients with severe scleroderma and/or soft tissue oedema.

Objectives: This study investigates the frequency of arthritis in SSc using musculoskeletal ultrasound (MSUS) compared to clinical investigation and in SSc.

Methods: Effusion, as well as synovitis in B- and PD-mode using MSUS was assessed in 31 consecutive patients with SSc; hand, finger, upper and lower ankle joints as well as metatarsophalangeal (MTP) joints were scanned totaling 1364 joints. In all patients carotid intima media thickness (CIMT) was assessed by Doppler ultrasound. Arthritis disease activity was assessed by the $\mathrm{HAQ}$, and the DAS66/68, respectively; joint pain and patient global health $(P G H)$ were quantified on a visual analogue scale (VAS). Skin involvement was measured using the modified Rodnan Skin Score (mRSS). CRF such as smoking, hypertension or positive family history were registered

Results: All patients were negative for ACPA and rheumatoid factors. 58.06\% $(n=18)$ of patients had joint pain, $22.58 \%(n=7)$ clinical joint swelling. In MSUS, 82 joints with effusion were detected in 23 patients ( $I^{\circ}: n=50$ joints, $I^{\circ}: n=32$ joints). 25 joints in 11 patients were detected by B-mode synovitis $\left(I^{\circ}: 9\right.$ joints, $I^{\circ}: 16$ joints). 7 joints in 3 patients showed PD-synovitis ( $\left(^{\circ}: 2\right.$ joints, $I^{\circ}: 5$ joints). In 10 patients MSUS could detect effusion where clinical examination could not; none of the clinically suspicious joints had effusion in MSUS. B-mode synovitis was detected in 3 clinically normal patients, in 6 patients with joint pain, and in 3 patients with joint pain and swelling. 1 patient with PD-synovitis each had TJC-/ SJC-, TJC+/SJC+, or TJC+/SJC- at clinical examination. The overall correlation of MSUS with clinical examination was poor ( $p>0.05)$. B-mode synovitis and PDmode synovitis prevailed the MTPs $(60 \%, n=15 \%$ and $85.71 \%, n=6$, respectively). For median nerves, a cutoff area of $>13 \mathrm{~mm}^{2}$ was deemed pathologic, $>11 \mathrm{~mm}^{2}$ and $<13 \mathrm{~mm}^{2}$ was intermediate. $11 / 31$ patients had either pathologic or intermediate median nerves. Doppler ultrasound found 10 pathological CIMT in 8 individual patients; carotid plaques were detected in 25 carotid arteries in 20 patients. Patients with CIMT and/or carotid plaques were elderly (60.52 years \pm 10.84 ), long term sick (156.48 \pm 123.19 months), and had at least one cardiovascular risk factor.

Conclusions: In patients with arthralgia MSUS could detect clinically not obvious arthritis. Especially in joints with soft tissue oedema and sclerotic skin MSUS was superior to clinical examination. Interestingly, arthritis was most frequently found in the MTP and wrist joints supporting recent data. ${ }^{1}$ In this small cohort there was no significant correlation between CRP positivity and arthritis. Not surprisingly, carotid plaques were more frequent in elderly and/or long-term patients with one or more CRF. We plan to pursue this investigation in a larger cohort.

\section{REFERENCE:}

[1] lagnocco A, et al. Power Doppler ultrasound of the hand and wrist joints in systemic sclerosis. Clin Exp Rheumatol. 2013 Mar-Apr;31(2 Suppl 76):8995

Disclosure of Interest: None declared

DOI: 10.1136/annrheumdis-2018-eular.7499

\section{FRI0564 ULTRASONOGRAPHIC EVALUATION OF SHOULDER TENDONS IN PATIENTS WITH HASHIMOTO'S DISEASE}

D.E. Buyuksireci ${ }^{1}$, D. Tecer ${ }^{2}$, B. Bolayir ${ }^{3}$, M.E.E. Yon ${ }^{4}$, M. Akturk ${ }^{3}$, F. Gogus ${ }^{5}$. ${ }^{1}$ Department of Physical Medicine and Rehabilitation, Gazi University Faculty of Medicine, Ankara; ${ }^{2}$ Department of Rheumatology, Mehmet Akif Inan Education and Research Hospital, Sanlıurfa; ${ }^{3}$ Department of Internal Medicine, Division of Endocrinology and Metabolism; ${ }^{4}$ Department of Internal Medicine; ${ }^{5}$ Department of Physical Medicine and Rehabilitation, Division of Rheumatology, Gazi University Faculty of Medicine, Ankara, Turkey

Background: Hashimoto's disease is an autoimmune disease characterised by autoantibody positivity in the blood and diffuse lympocyte infiltration in the thyroid. Thyroxine is an important hormone in collagen and matrix metabolism. Low levels of thyroid hormones or antibodies positivity may lead to tendon pathologies and subsequent shoulder pain in patients with Hashimoto's disease.

Objectives: 1)To investigate tendon thickness and pathologies in patients with Hashimoto's disease. 2) To investigate if shoulder pain in Hashimoto's disease is associated with ultrasonographic tendon pathologies.

Methods: Assuming a $0.5 \mathrm{~mm}$ mean difference and $0.7 \mathrm{~mm}$ SD of thickness at rotator cuff tendons with $80 \%$ power and $5 \%$ significance 119 female subjects (40 patients euthyroid Hashimoto's disease, 28 subclinical hypothyroid Hashimoto's disease and 51 healthy subjects) were recruited. ${ }^{1}$ Participants were divided into three groups: Group 1: patients with subclinical hypothyroid Hashimoto's disease Group 2: patients with euthyroid Hashimoto's disease, Group 3: healthy controls. A rheumatologist experienced in musculoskeletal ultrasonography and blind to clinical data of the patients evaluated the thickness of biceps, subscapularis, supraspinatus, infraspinatus tendons at both shoulders according to standard pro tocol. ${ }^{2}$ The presence of subacromial bursitis, effusion, tendon rupture or tendinosis were recorded. The participants of TSH (thyroid stimulated hormone), free T3 (triiodothyronine), free T4 (thyroxine), anti TPO (thyroid peroxidase) and anti TG (thyroglobulin) antibodies levels were measerud. In addition the presence and duration of shoulder pain of the participants were recorded.

Results: Height, weight, BMI (body mass index), free T3 and free T4 levels were similar between three groups $(p=0.830, p=0.205, p=0.374, p=0.430$ and $p=0.497$ respectively). Tendon thicknesses in patient groups are presented in table 1. Biceps brachii, subscapularis, supraspinatus and infraspinatus tendon thicknesses were increased significantly in both euthyroid Hashimoto's disease and subclinical hypothyroid Hashimoto's disease groups at dominant and non- dominant arms compared to healthy controls. However there was no such difference between euthyroid Hashimoto's disease and subclinical hypothyroid Hashimoto's disease groups. There was no correlation between levels of TSH, anti TPO, ant TG and tendon thickness. Two participants in three groups had shoulder pain for 1-3 months. These participants had no ultrasonographic shoulder tendon pathology.

Abstract FRI0564 - Table 1. Differences between euthyroid Hashimoto's disease, subclinical hypothyroid Hashimoto's disease and health controls in dominant and nondominant arms.

\begin{tabular}{|c|c|c|c|c|c|c|c|}
\hline & $\begin{array}{l}\text { Group } 1 \\
(\mathrm{n}=28)\end{array}$ & $\begin{array}{l}\text { Group } 2 \\
(\mathrm{n}=40)\end{array}$ & $\begin{array}{l}\text { Group } 3 \\
(\mathrm{n}=51)\end{array}$ & $\begin{array}{l}P \\
\text { value }\end{array}$ & value* $^{\mathbf{p}}$ & $\begin{array}{l}\text { p } \\
\text { value** }\end{array}$ & $\begin{array}{l}\text { P } \\
\text { value*** }\end{array}$ \\
\hline \multicolumn{8}{|l|}{ Dominant arm } \\
\hline Biseps brachii & $.39 \pm 0.63$ & $2.64 \pm 0.65$ & $2.24 \pm 0.43$ & 0.007 & 0.798 & 0.004 & 0.019 \\
\hline Subscapularis & $4.09 \pm 0.89$ & $3.96 \pm 0.64$ & $3.66 \pm 0.52$ & 0.017 & 0.397 & 0.021 & 0.018 \\
\hline Supraspinatus & $4.90 \pm 0.80$ & $4.96 \pm 0.99$ & $4.50=0.72$ & 0.034 & 0.410 & 0.032 & 0.028 \\
\hline Infra & $1.96 \pm 0.81$ & $2.16 \pm 0.84$ & $1.52+0.28$ & 0.000 & 0.847 & 0.000 & 0.020 \\
\hline Acromiohumeral & $10.57 \pm 1.09$ & $10.25 \pm 1.40$ & $10.41 \pm 1.28$ & 0.419 & 0.176 & 0.592 & 0.436 \\
\hline \multicolumn{8}{|l|}{ Non-dominant arm } \\
\hline $\begin{array}{l}\text { Non-dominant arm } \\
\text { Biseps brachii }\end{array}$ & $2.59 \pm 0.61$ & 2.48 & 2.24 & 0.030 & 0.798 & 0.020 & 0.040 \\
\hline Subs & $4.21 \pm$ & $4.06 \pm$ & 3.74 & 0.018 & 0.516 & 0.023 & 0.016 \\
\hline & $4.80=$ & 4.84 & 4.44 & 0.022 & 0.793 & 0.025 & 0.017 \\
\hline Infraspinatu & $2.07 \pm 0.95$ & $2.05 \pm 0.81$ & $1.55 \pm 0.31$ & 0.001 & 0.476 & 0.000 & 0.043 \\
\hline $\begin{array}{l}\text { Acromiohumeral } \\
\text { distance }\end{array}$ & $10.53 \pm 1.03$ & $10.21 \pm 1.29$ & $10.25 \div 1.33$ & 0.363 & 0.162 & 0.990 & 0.224 \\
\hline \multicolumn{8}{|c|}{$\begin{array}{l}\text { Data are presented as the mean } \pm \text { standart deviation. All data are presented in millimeters. P< } \\
0,05 \text {. Group 1: subclinical hypothyroid Hashimoto's disease; Group 2: euthyroid } \\
\text { Hashimoto's disease; Group 3: Healthy controls }\end{array}$} \\
\hline \multicolumn{8}{|c|}{$\begin{array}{l}\text { p value* difference between patients with euthyroid Hashimoto's disease and subclinical } \\
\text { hypothyroid Hashimoto's disease }\end{array}$} \\
\hline \multicolumn{8}{|l|}{$\begin{array}{l}\text { p value** } \\
\text { controls }\end{array}$} \\
\hline $\begin{array}{l}\text { p value } \\
\text { healthy }\end{array}$ & ence & patie & bel & othy & & & \\
\hline
\end{tabular}

Conclusions: Presence of autoimmun thyroid disease may lead to increased shoulder tendon thickness. However increase in tendon thickness is not seemed to be associated with shoulder pain.

\section{REFERENCES:}

[1] Kim K, et al. Ultrasound Dimensions of the Rotator Cuff and Other Associated Structures in Korean Healthy Adults. Journal of Korean medical science 2016;31(9):1472-1478.

[2] Schmidt WA, Schmidt H, Schicke B, Gromnica-Ihle E. Standart references values for musculoskeletal ultrasonography. Ann Rheum Dis 2004;63:988994.

Disclosure of Interest: None declared DOI: 10.1136/annrheumdis-2018-eular.4807 